Supporting Information

\title{
Charged poly $(N$-isopropylacrylamide) nanogels for the stabilization of high isoelectric point proteins
}

Laura J. Macdougall, ${ }^{1,2,+}$ Marissa E. Wechsler, ${ }^{1,2,+}$ Heidi R. Culver, ${ }^{l}$ Evan H. Benke, ${ }^{l}$ Adam Broerman, ${ }^{l}$ Christopher N. Bowman ${ }^{l}$ and Kristi S. Anseth ${ }^{1,2 *}$

${ }^{1}$ Department of Chemical and Biological Engineering ${ }^{2}$ The BioFrontiers Institute, University of Colorado, Boulder, Jennie Smoly Caruthers Biotechnology Building, 3415 Colorado Ave, Boulder, CO, 80303

Table of Contents:

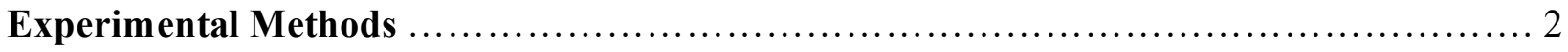

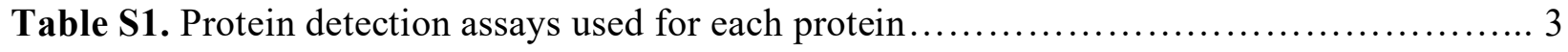

Figure S1. Percent adsorption of proteins with various isoelectric points and molecular weights. 4

Figure S2. Adsorption capacity (Q) of proteins with different isoelectric points and molecular

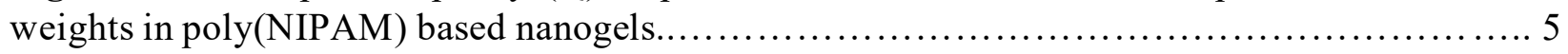

Figure S3. Effect of ionic strength and buffer concentration on the release of cytochrome $\mathrm{C}$ from poly(NIPAM-co-MAA) nanogels........................................................... 6

Figure S4. Release of proteins of various isoelectric points from poly(NIPAM) based nanogels

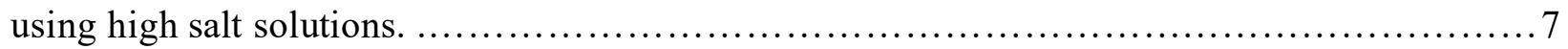

Figure S5. Activity and release of various proteins from poly(NIPAM-co-MAA) nanogels...... 8

Figure S6. Stabilization of protected and unprotected proteins at room temperature over 14

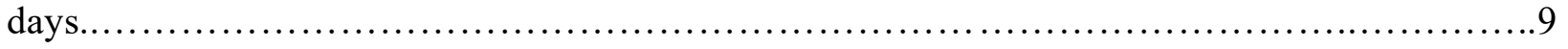

Figure S7. Protection of adsorbed proteins against environmental stresses....................10 


\section{Experimental Methods}

Equine based protein binding and release studies. Protein binding studies were conducted as previously described. ${ }^{1}$ Briefly, anionic poly(NIPAM-co-MAA) or cationic poly(NIPAM-coAPMA) nanogels were suspended at $1 \mathrm{mg} / \mathrm{mL}$ in $0.1 \mathrm{X}$ HBS at room temperature. Horse $\mathrm{IgG}$ (Molecular Innovations, Novi, MI) or AffiniPure $\mathrm{F}\left(\mathrm{ab}^{\prime}\right)_{2}$ Fragment Donkey Anti-Goat IgG (Jackson ImmunoResearch Laboratories, Inc., West Grove, PA) was buffer exchanged into 0.1X HBS using centrifugal filter devices (Microcon, $\mathrm{MWCO}=10 \mathrm{kDa}$ ). The buffer exchanged protein was diluted $(0-5 \mathrm{mg} / \mathrm{mL})$ and combined with the nanogel solutions in a 1:1.5 volume ratio. Controls were nanogels combined with $0.1 \mathrm{X}$ HBS in the absence of protein. Nanogels and any bound protein were centrifuged $(17,000 \mathrm{~g}, 20 \mathrm{~min})$ and the concentration of protein in the supernatant (un-bound protein) was determined by absorbance at $280 \mathrm{~nm}(100 \mu \mathrm{L})$ using a plate reader (Synergy H1 microplate reader, BioTek). The adsorption capacity (Q) was calculated using equation 1.

$$
\mathrm{Q}=\frac{\left(\mathrm{C}_{0}-\mathrm{C}_{\mathrm{e}}\right) \mathrm{V}}{\mathrm{m}}
$$

Here, $\mathrm{C}_{0}$ and $\mathrm{C}_{\mathrm{e}}$ are the initial and equilibrium protein concentrations $(\mathrm{mg} / \mathrm{mL})$, respectively; $\mathrm{V}$ is the total volume $(\mathrm{mL})$; and $\mathrm{m}$ is the mass of nanogels used $(\mathrm{mg})$.

Protein release was conducted by disrupting electrostatic interactions of the pelleted proteinnanogel complex using $40 \mathrm{mM} \mathrm{CaCl}$. Solutions were then centrifuged (14,000 $\mathrm{g}, 10 \mathrm{~min})$ to pellet the nanogels leaving the released protein in the supernatant. Protein quantification was determined by absorbance at $280 \mathrm{~nm}(100 \mu \mathrm{L})$. The percent released protein was calculated using equation 2 :

$$
\% \text { Release }=\frac{\mathrm{C}_{\text {released }}}{\left(\mathrm{C}_{0}-\mathrm{C}_{\mathrm{e}}\right)} \times 100 \%
$$

where $\mathrm{C}_{\text {released }}$ is the protein concentration in the high salt solution after centrifuging. $\mathrm{C}_{0}$ and $\mathrm{C}_{\mathrm{e}}$ are defined in equation 1. 
Supplementary figures

Table S1. Protein detection assays used for each protein.

\begin{tabular}{cc}
\hline Protein & Protein assay \\
\hline Ovalbumin & Pierce 660 \\
Lactase & Pierce 660/ Nanodrop \\
Bovine serum albumin & \\
(BSA) & Pierce 660 \\
Alcohol dehydrogenase & \\
(ADH) & Pierce 660 \\
Human Immunoglobulin G & \\
(IgG) & Absorbance at $280 \mathrm{~nm}$ \\
Lactate Dehydrogenase & \\
(LDH) & Pierce 660 \\
Papain & \\
\hline
\end{tabular}



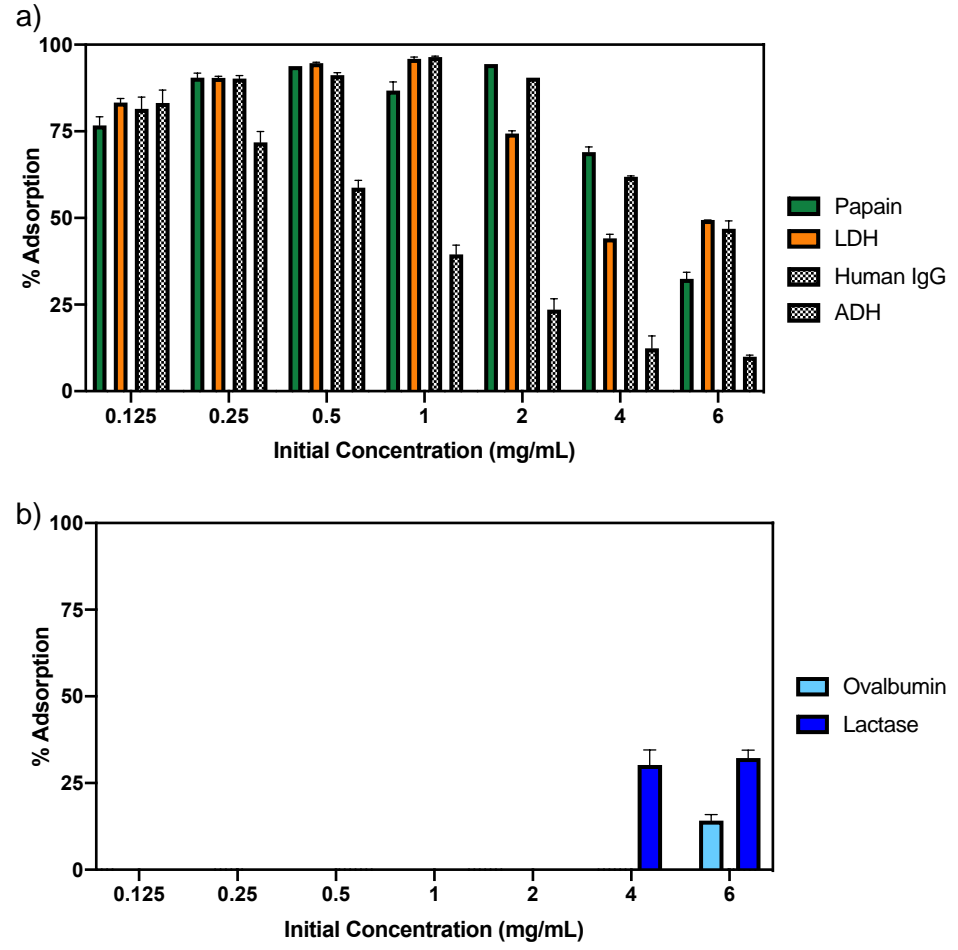

Figure S1. Percent adsorption of proteins with various isoelectric points and molecular weights. Adsorption into a) poly(NIPAM-co-MAA) nanogels in $0.1 \mathrm{X}$ PBS at pH 7.4 (solid bars) or 0.1X HBS, pH 5.5 (hashed bars), b) poly(NIPAM-co-APMA) nanogels in 0.1X PBS at pH 7.4 . 
a)

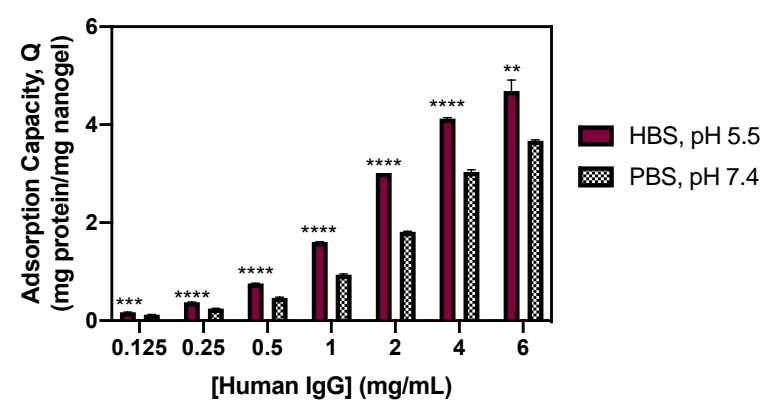

b)

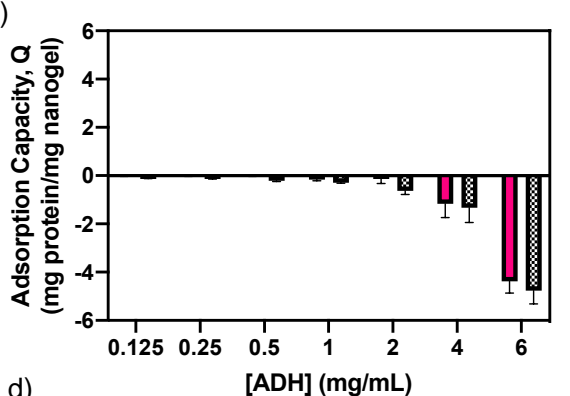

c)

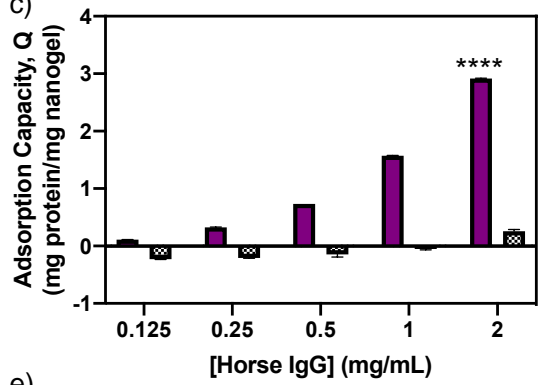

Poly(NIPAM-Co-MAA)

Poly(NIPAM-co-APMA)

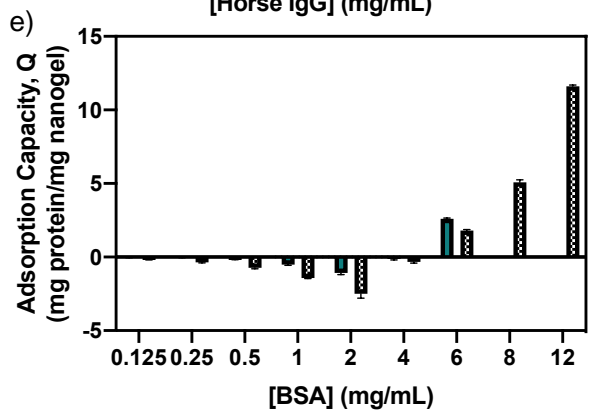

Figure S2. Adsorption capacity (Q) of proteins with different isoelectric points and molecular weights to poly(NIPAM) based nanogels. a) Adsorption of IgG to poly(NIPAM-co-MAA) in various buffers, b) Adsorption of $\mathrm{ADH}$ in $0.1 \mathrm{X}$ PBS, c) Adsorption of horse IgG in $0.1 \mathrm{X} \mathrm{HBS} \mathrm{pH}$ 5.5, d) Adsorption of donkey $\mathrm{F}\left(\mathrm{ab}^{\prime}\right)_{2}$ in $0.1 \mathrm{X} \mathrm{HBS} \mathrm{pH} 5.5$, e) Adsorption of BSA in $0.1 \mathrm{X} \mathrm{PBS} \mathrm{pH}$ 7.4. Solid bars represent protein adsorbed to poly(NIPAM-co-MAA) nanogels and hashed bars represent protein adsorbed to poly(NIPAM-co-APMA) nanogels. Data shown as mean $(\mathrm{n}=3) \pm$ SD. Data were analyzed using unpaired t tests. $*=\rho<0.05 * *=\rho<0.005 * * *=\rho<0.0005 * * * *$ $=\rho<0.00005$. 

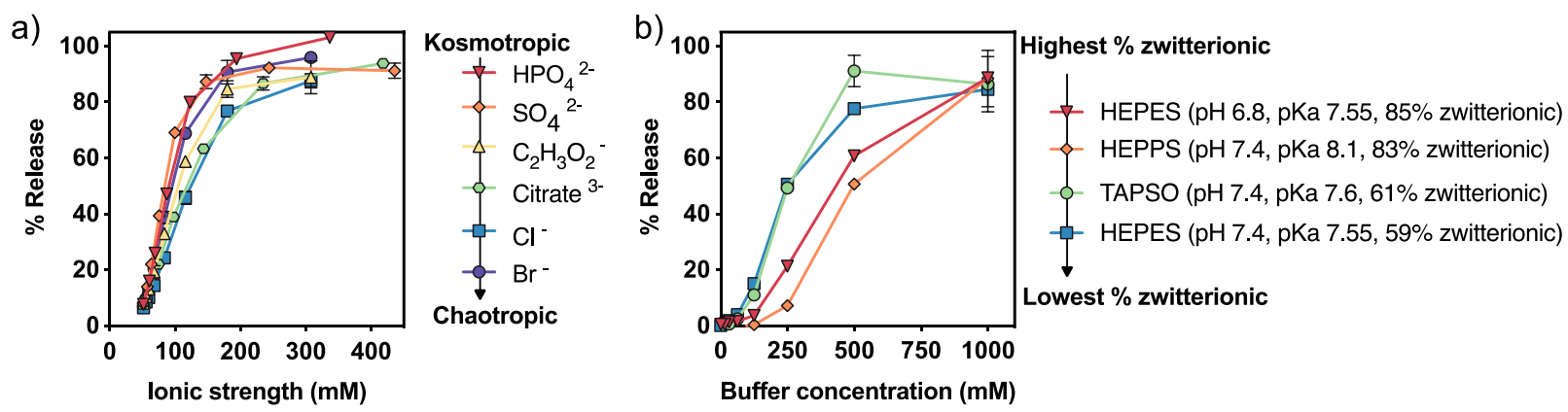

Figure S3. Effect of ionic strength and buffer concentration on the release of cytochrome $\mathrm{C}$

from poly(NIPAM-co-MAA) nanogels. Effect of: a) ionic strength of anions, and b) zwitterionic percent and buffer concentration of protein release. Data shown as mean $(n=3) \pm S D$. 

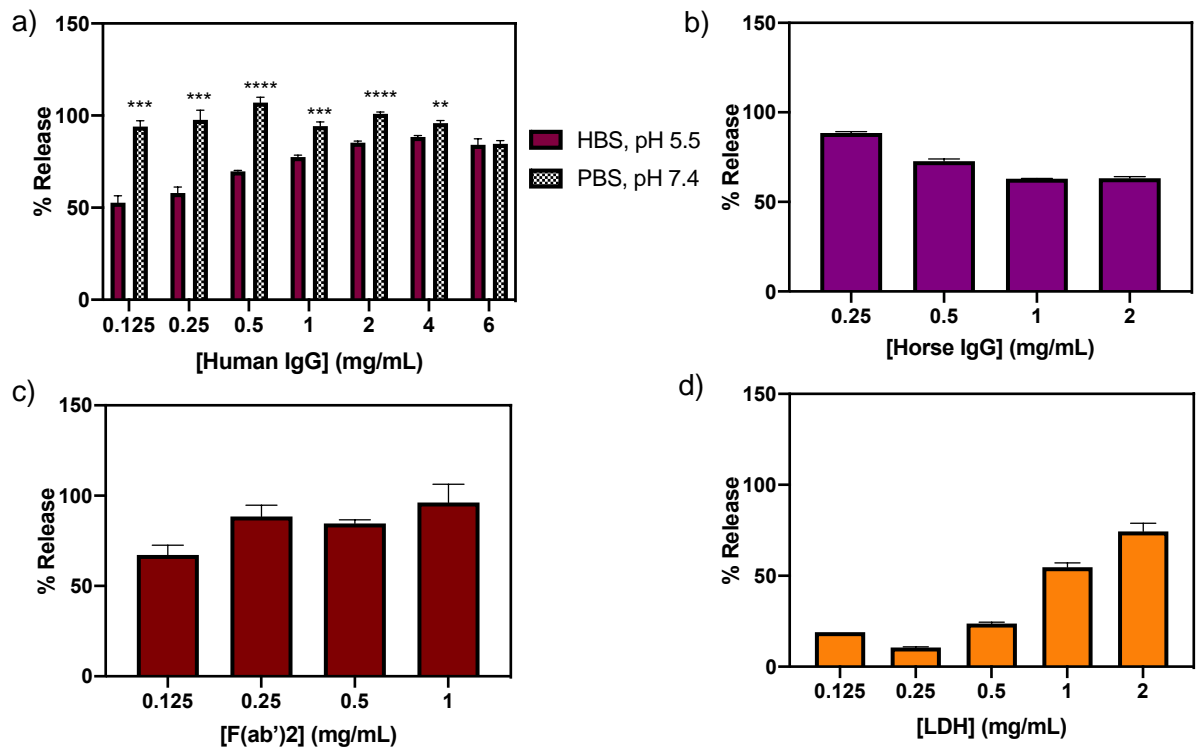

d)
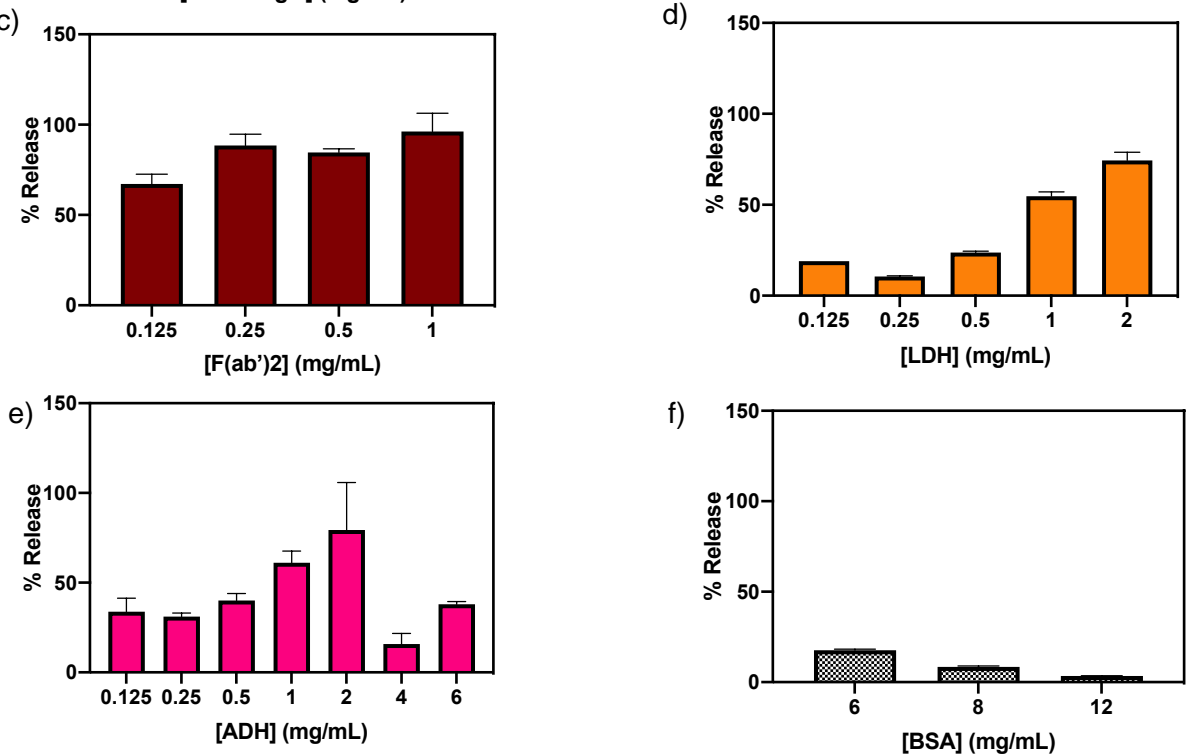

Figure S4. Release of proteins of various isoelectric points from poly(NIPAM) based nanogels using high salt solutions. a) Release of human IgG from poly(NIPAM-co-MAA) using 40mM $\mathrm{CaCl}_{2}$, adsorbed in either 0.1X HBS (solid bars) or 0.1X PBS (hashed bars). b) Release of horse IgG from poly(NIPAM-co-MAA) nanogels using $40 \mathrm{mM} \mathrm{CaCl}_{2}$, c) Release of $\mathrm{F}(\mathrm{ab})_{2}$ from poly(NIPAM-co-MAA) nanogels using $40 \mathrm{mM} \mathrm{CaCl}_{2}$, d) Release of LDH from poly(NIPAM-coMAA) nanogels using $40 \mathrm{mM} \mathrm{CaCl} 2$, e) Release of ADH from poly(NIPAM-co-MAA) nanogels using $40 \mathrm{mM} \mathrm{CaCl}_{2}$, f) Release of BSA from poly(NIPAM-co-APMA) nanogels using $1 \mathrm{M} \mathrm{NaCl}$. Data shown as mean $(\mathrm{n}=3) \pm \mathrm{SD}$. Data were analyzed using unpaired t tests. $*=\rho<0.05 * *=\rho$ $<0.005 * * *=\rho<0.0005 * * * *=\rho<0.00005$. 
a) i)

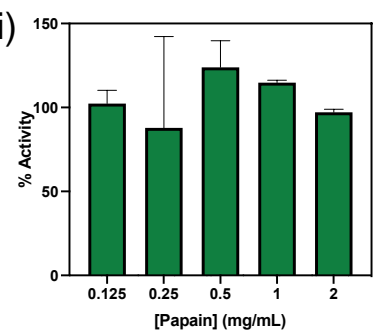

b) i)

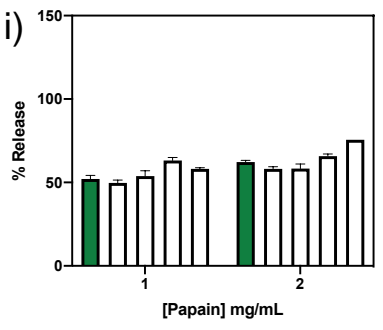

ii)
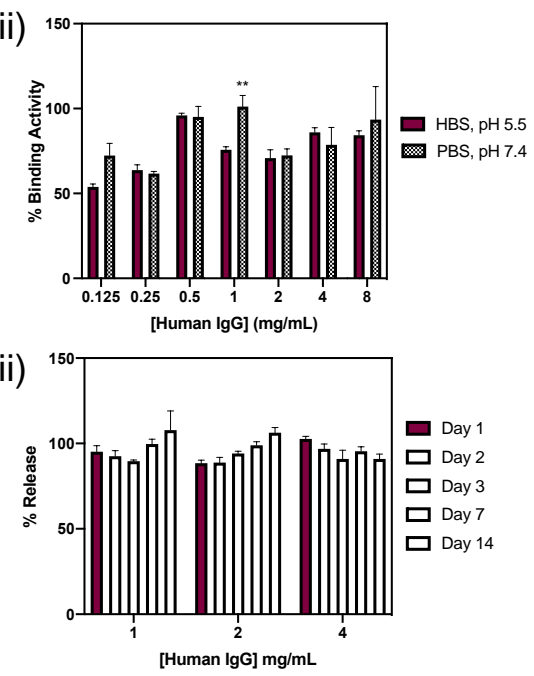

c)

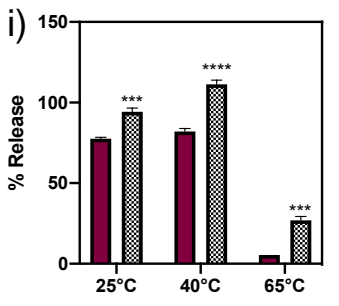

ii)

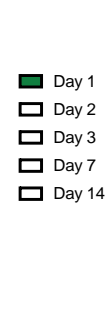

ii)

ii)

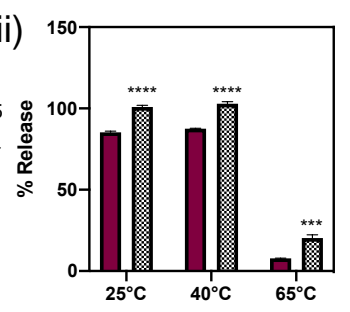

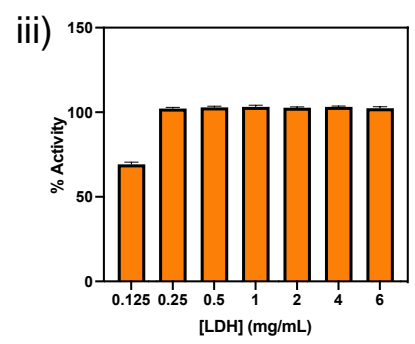

iii)
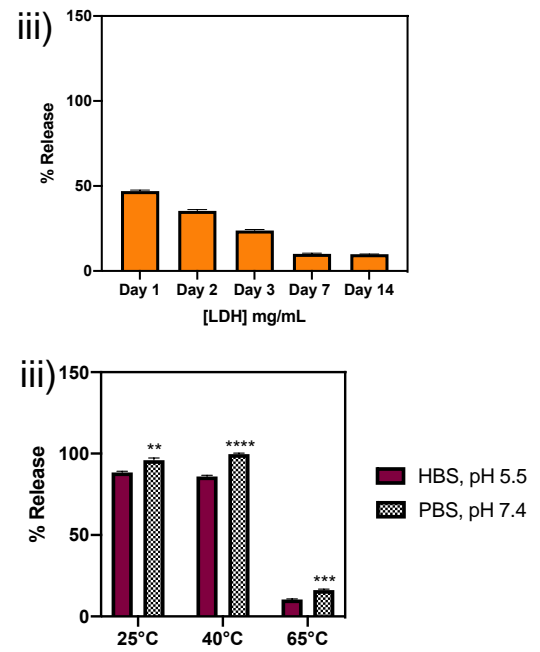

Figure S5. Activity and release of various proteins from poly(NIPAM-co-MAA) nanogels. a)

Activity of proteins after release: i) Papain adsorbed in 0.1X PBS, ii) Human IgG adsorbed in either 0.1X HBS (solid bars) or 0.1X PBS (hashed bars), iii) LDH adsorbed in 0.1X PBS, b) Release of proteins over time at different initial concentrations: i) Papain released using $40 \mathrm{mM}$ $\mathrm{CaCl}_{2}$ ii) Human $\mathrm{IgG}$ released using $40 \mathrm{mM} \mathrm{CaCl}_{2}$ iii) $\mathrm{LDH}$ released using $20 \%$ saturated $\left.\left(\mathrm{NH}_{4}\right)_{2} \mathrm{SO}_{4}\right)$ at $1 \mathrm{mg} / \mathrm{mL}$. c) Percent release of Human $\mathrm{IgG}$ adsorbed in either $0.1 \mathrm{X}$ HBS, pH 5.5 (solid bars) or 0.1X PBS pH 7.4 (hashed bars) after exposure to different temperatures for 30 mins: i) $1 \mathrm{mg} / \mathrm{mL}, 2 \mathrm{mg} / \mathrm{mL}$, iii) $4 \mathrm{mg} / \mathrm{mL}$. Data shown as mean $(\mathrm{n}=3) \pm \mathrm{SD}$. Data were analyzed using unpaired t tests. $*=\rho<0.05 * *=\rho<0.005 * * *=\rho<0.0005 * * * *=\rho<0.00005$. 
a) i)

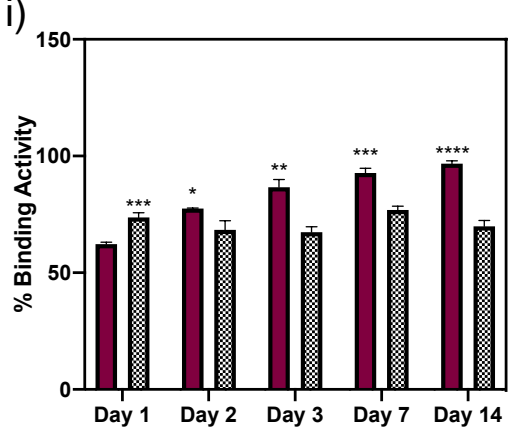

b)

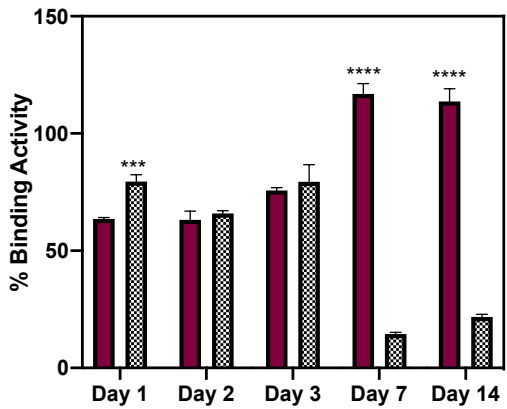

ii)

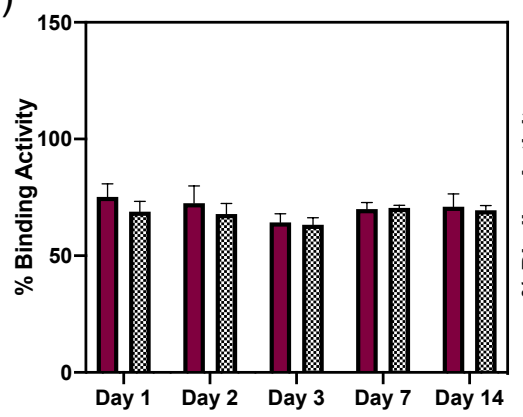

c) i)

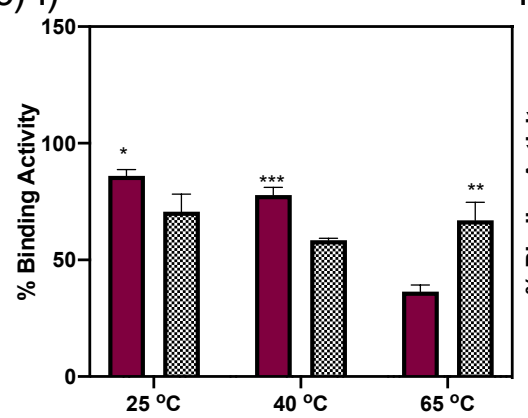

iii)

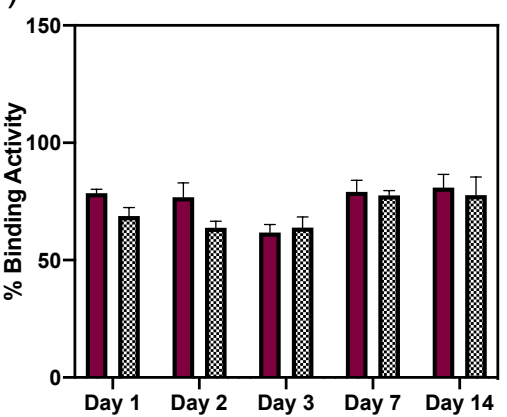

ii)

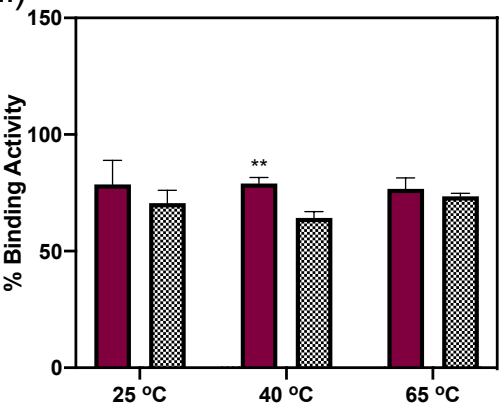

Protected

Unprotected

Figure S6. Protection of Human IgG released using $40 \mathrm{mM} \mathrm{CaCl}_{2}$ against environmental stresses. Proteins protected by poly(NIPAM-co-MAA) nanogels. Unprotected proteins in buffer alone in the absence of nanogels. a) Stabilization of protected and unprotected proteins at room temperature over 14 days adsorbed in $0.1 \mathrm{X}$ PBS, pH 7.4 at i) $1 \mathrm{mg} / \mathrm{mL}$, ii) $2 \mathrm{mg} / \mathrm{mL}$, iii) $4 \mathrm{mg} / \mathrm{mL}$. b) Stabilization of protected and unprotected proteins at room temperature over 14 days adsorbed in $0.1 \mathrm{X} \mathrm{HBS}$, pH 5.5 at $1 \mathrm{mg} / \mathrm{mL}$. c) Protection of human $\mathrm{IgG}$ in response to various elevated temperatures for $30 \mathrm{mins}$ at $4 \mathrm{mg} / \mathrm{mL}$ in i) $0.1 \mathrm{X} \mathrm{HBS}$, ii) $0.1 \mathrm{X}$ PBS. Solid bars represent protein adsorption protected protein - nanogel complexes and hashed bars represent unprotected proteins. Data shown as mean $(\mathrm{n}=3) \pm \mathrm{SD}$. Data were analyzed using unpaired t tests. $*=\rho<0.05 * *=\rho$ $<0.005 * * *=\rho<0.0005 * * * *=\rho<0.00005$. 
a)

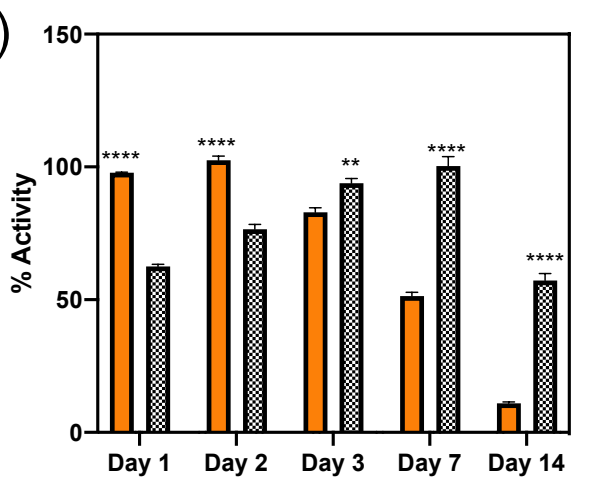

$\square$ Protected

m Unprotected

b) i)

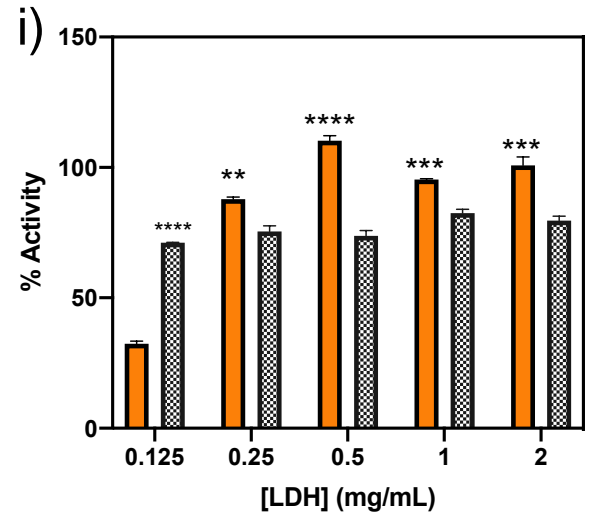

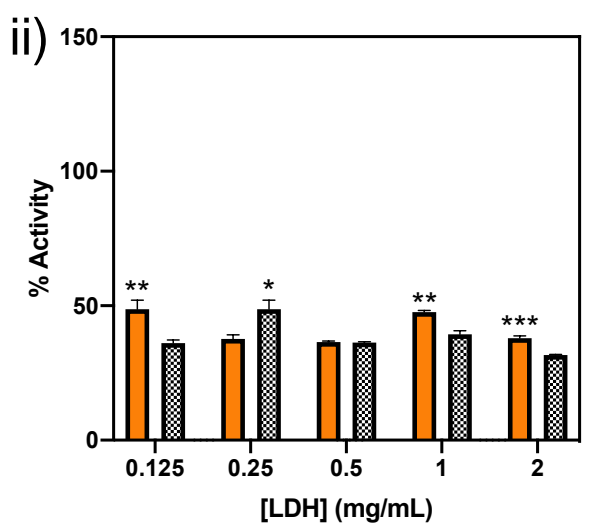

Figure S7. Protection of adsorbed proteins against environmental stresses. Protection of adsorbed LDH against environmental stresses. Proteins protected by poly(NIPAM-co-MAA) nanogels. Unprotected proteins in buffer alone in the absence of nanogels. a) Room temperature stability over 14 days at $1 \mathrm{mg} / \mathrm{mL}$ b) \% Activity of LDH at different concentrations i) after heating to $40^{\circ} \mathrm{C}$ for 30 mins ii) lyophilization. Solid bars represent protein adsorption protected protein nanogel complexes and hashed bars represent unprotected proteins. Data shown as mean $(n=3) \pm$ SD. Data were analyzed using unpaired t tests. $*=\rho<0.05 * *=\rho<0.005 * * *=\rho<0.0005 * * * *$ $=\rho<0.00005$. 